\title{
MASACCIO, CULTURA CRISTÃ NO PRIMEIRO RENASCIMENTO: A INTERPRETACÃO CRITTICA DE GIULIO CARLO ARGAN E A EXEGESE DA FORMA
}

\author{
MASACCIO, CHRISTIAN CULTURE IN THE FIRST \\ RENAISSANCE: THE CRITICAL INTERPRETATION OF \\ GIULIO CARLO ARGAN AND THE EXEGESIS OF THE \\ FORM
}

João Cícero Teixeira Bezerra ${ }^{1}$ 


\section{Resumo}

O artigo analisa a relação entre a cultura cristã e a forma perspectiva na obra de Masaccio no primeiro Renascimento, a partir de uma interpretação do historiador italiano Giulio Carlo Argan. Para isso, discute-se o debate teológico da forma total presente nos escritos de São Pedro Damião a fim de especular possibilidades interpretativas para o surgimento da forma perspectiva em Florença no século XV. Outros historiadores como Frederick Antal, Ernst Gombrich, Ernst Panofsky são solicitados para dialogar com a interpretação de Argan. Assim sendo, o ensaio segue dois caminhos: 1ㅇ - apresenta a obra de Masaccio no contexto do Renascimento, e 2ㅇ- debate sobre o método historiográfico do historiador italiano.

Palavras-chave: Historiografia. História da Arte. Renascimento.

\section{Abstract}

This article analyzes the relationship between Christian culture and the perspective form in the work of Masaccio during the first Renaissance, based on an interpretation of the Italian historian Giulio Carlo Argan. For this reason, the theological debate of the total form present in St. Peter Damian's writings is discussed in order to speculate interpretative possibilities for the emergence of perspective form in Florence in the 15th century. Other historians such as Frederick Antal, Ernst Gombrich, Ernst Panofsky are asked to dialogue with Argan's interpretation. Thus, the essay follows two paths: 1st - it presents a work by Masaccio in the context of the Renaissance, and 2nd - it debates on the historiographic method of the Italian historian.

Keywords: History. Art history. Renaissance

ISSN: 2175-2346 


\section{A tradição e os dilemas da representação}

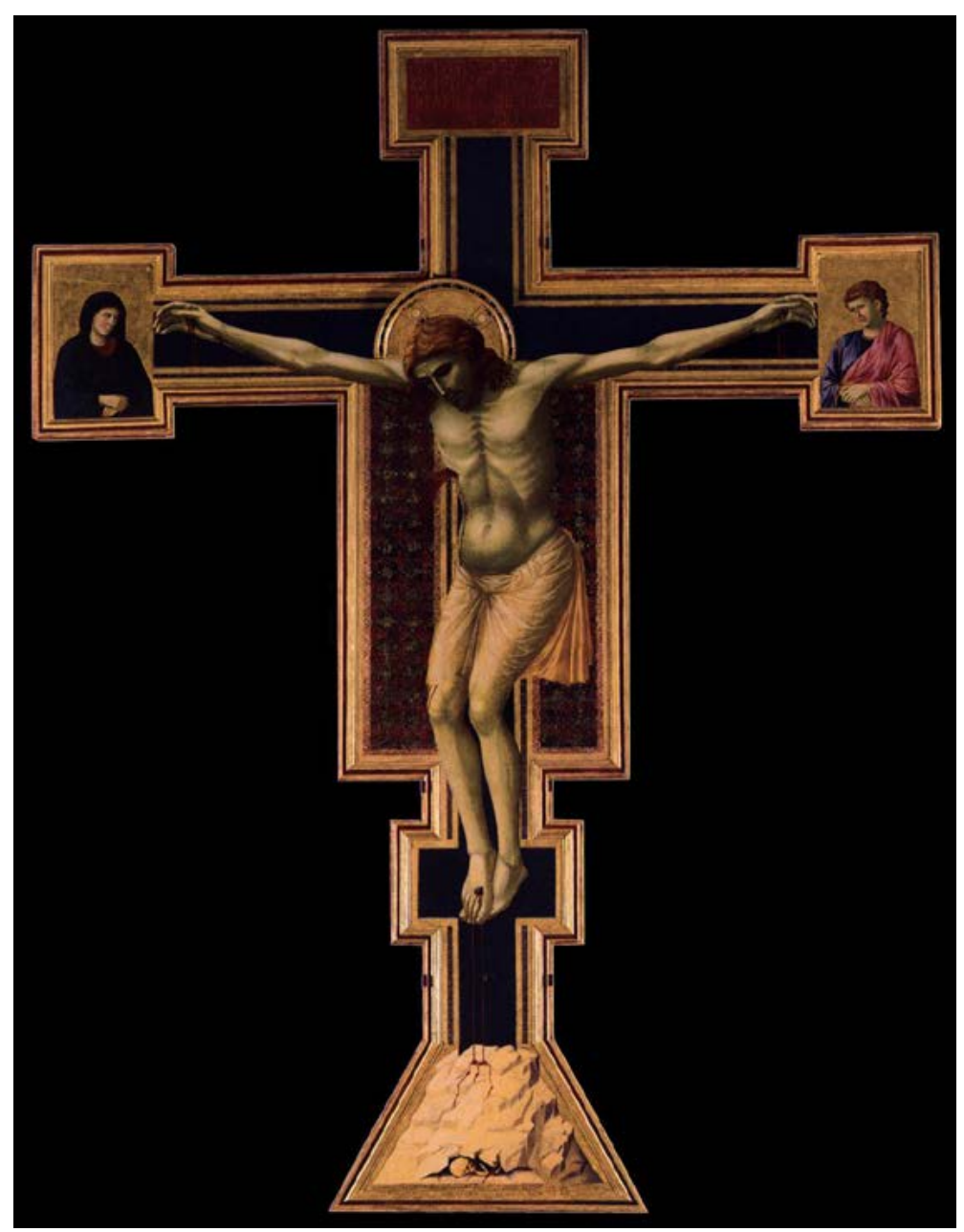

Fig.1 - GIOTTO. Crucifixo. Têmpera sobre madeira, 578 x $406 \mathrm{~cm}$. Florença, Igreja de Santa Maria Novella. Fonte: Web Gallery of Arts - <www.wga.hu> acesso em 14/03/2015.

Um século praticamente se passou da obra de Giotto até a de Masaccio. $O$ primeiro formalizou a síntese de um Renascimento da cultura latina dentro da cultura gótica. O segundo capturou o sentido de síntese presente na obra deste pintor dos trezentos, unindo-o à descoberta da perspectiva de Brunelleschi (ARGAN, 2003, p. 20-22). Como não nos interessa apenas a confirmação da síntese, e sim acompanhar a urdidura do historiador Giulio Carlo Argan na construção dessa visada, tocaremos em um ponto que nos parece basilar: a representação. E o exemplo para esta análise será o crucifixo pintado por Giotto e Masaccio. Sobre o crucifixo de Giotto (Figura 1), Argan diz:

Não há dúvida de que a imagem com o coeficiente máximo de representatividade, para a cultura dos duzentos na Itália Central, é a imagem do crucifixo: isolada de qualquer história, repropõe à meditação e à piedade dos fiéis ao espetáculo, trágico e eterno de Cristo, Deus-homem que sofre para resgatar os pecados da humanidade. (...) No Crucifixo de Santa Maria Novella - pintado no fim do século XII ou nos primeiros anos dos trezentos - Giotto, com um ato revolucionário, reduz a zero o grau de iconicidade da imagem. Representando as mãos em escorço, insere o corpo de Cristo - um corpo pesado que não se dobra gritando, mas que se abaixa sob o próprio peso - em nosso espaço e tempo: o ser da imagem é um ser-em-relação com o observador, a apresentação icônica torna-se representação histórica (ARGAN, 2003, p. 25). 
No fragmento há uma reflexão sobre a representação política do crucifixo na cultura dos duzentos. Mas o conceito de representação, neste trecho, possui dois significados precisos: representatividade política e representatividade real (histórica). Política porque o crucifixo congrega em torno de si uma legião de fiéis vinculados à igreja. Histórico porque, quando Giotto constrói seu crucifixo com a imagem de um Cristo humanizado, dotado de peso corpóreo (em uma criação dramática em que causa-efeito da crucificação se veem refletidos no corpo do Cristo morto), ele oferece aos observadores a imagem de um Cristo terreno - que venceu a matéria, mas cumpriu sua missão dolorosa de viver em um corpo mortal, histórico. No caso, a revolução de Giotto seria a de transformar a iconicidade da imagem do crucifixo em um "ser-em-relação" com o observador, mostrando o Cristo como um ser-humano-histórico mais do que como uma divindade não perecível (que antes era, predominantemente, manifestada por meio do ícone).

Masaccio, apesar de ter sido discípulo de Masolino, com o qual colaborou diversas vezes, como diz Giorgio Vasari (VASARI, 2011, p. 219), aproxima-se mais de Giotto do que de seu mestre. Isto se deve ao fato de ambos terem produzido uma ruptura no seio da cultura artístico-religiosa de Florença, que teve em Giotto e Masaccio o fundamento de uma grande transformação plástica e ética. Acerca disto, Argan diz: "Qual a margem de interpretação do artista do começo do século XV? A partir de Giotto, os artistas reivindicaram o direito à livre interpretação dos fatos sagrados" (ARGAN, 2011, p. 36). A liberdade de interpretação dada aos pintores não reorganiza apenas as passagens bíblicas, dando-lhe novas versões, mas está calcada, sobretudo, em um debate teológico amplo sobre a forma e a representação surgidas em Florença, como o historiador nos mostra abaixo:

Por que o conceito de forma total foi tão cultivado em Florença? É uma ideia que remonta, sem dúvida, ao pensamento de São Pedro Damião (século XI), que se opunha a toda teologia filosófica e argumentativa, afirmando que a verdade religiosa revela-se na evidência literal da forma, e não na argumentação que a demonstra (ARGAN, 2011, p. 42).

Esta breve passagem está no ensaio intitulado "O primeiro Renascimento", em que Giulio Carlo Argan inicia a discussão sobre Masaccio. A escolha por este comentário inicial já é suficientemente significativa para que se entenda o caminho argumentativo do historiador. $O$ contexto apresentado por ele mostra o surgimento de uma vertente teológica fortemente difundida em Florença, que defendia o predomínio da forma totalizadora em lugar de uma demonstração argumentativa - forma total que problematiza até mesmo os domínios da lógica, da gramática e das ciências (RESNICK, 1992, p. 1).

São Pedro Damião, um importante doutor da igreja católica, fundamentou sua doutrina a partir de vários escritos. O mais importante chama-se De Divina Omnipotentia. Nele, São Pedro Damião defende o poder absoluto de Deus, respondendo afirmativamente acerca de uma querela medieval: a possibilidade de Deus restaurar a virgindade de uma jovem (RESNICK, 1992, p. 1). Deste modo, é possível a Deus, mediante sua onipotência, mudar até mesmo o passado, transformando realidades e fatos. Entretanto, conforme atesta o historiador da religião Irven Resnick em seu livro 
Divine power \& possibility in St. Peter Damian's De Divina Omnipotentia: "Damian's principal interest in his discussion of omnipotence is not speculative and abstract" [o principal interesse da discussão da onipotência divina em São Pedro Damião não é especulativo e nem abstrato]. "His concerns are extremely practical" [suas preocupações são extremamente práticas] (RESNICK, 1992, p. 2).

Feito por um historiador da religião, o comentário nos dá subsídio para que captemos o quanto este sentido total de forma possui um intuito doutrinário e prático. $A$ ilogicidade observável do ponto de vista histórico-cronológico presente neste poder divino de restauração da virgindade de uma jovem torna-se, na verdade, uma lógica submetida à confirmação da máxima do poder absoluto de Deus. Em certa medida, "inicia-se" a partir de São Pedro Damião uma aproximação da onipotência de Deus com a possibilidade de se imaginar/visualizar uma forma total - e há, nesta prerrogativa divina, uma retomada do neoplatonismo, como menciona o historiador italiano (ARGAN, 2011, p. 42). Tal conceito acaba sendo prático e doutrinário na medida em que finaliza toda a aporia em torno das dúvidas que cercavam a onipotência divina. Há nesta conceituação a ideia de que o poder de Deus é tão pleno a ponto de romper com os limites de tempo-espaço, o que nos faz pressentir as possíveis associações entre a síntese espacial ilusionística inventada no Renascimento e a paradoxal forma total originada no conceito de onipotência divina de São Pedro Damião, esta é uma hipótese do texto de Giulio Carlo Argan.

Seguindo no desenvolvimento do pensamento acerca da forma total de São Pedro Damião hipoteticamente lançado por Giulio Carlo Argan, vale citar o historiador da filosofia português Mario A. Santiago de Carvalho. Ele escreve o seguinte sobre a obra de São Pedro Damião:

Acresce que depois que a tomar-se a sério a afirmação da omnipotência divina, tão essencial à concepção judaico-cristã, para Deus nada deveria ser em teoria impossível. É conhecido a este propósito o esforço teológico de Pedro Damião (1007-1072), que naquele que foi o primeiro tratado consistente sobre a omnipotência divina afirmava poder Deus fazer com que o passado não tivesse passado. Logo, ainda que teoricamente, a fortiori devesse igualmente ser admitida a possibilidade do vazio (CARVALHO, 1992, p. 365-366).

Este comentário elucida o quanto a concepção de São Pedro Damião, ao acentuar a onipotência divina, possibilita a existência de um paradoxo lógico dentro do universo: o Deus que pode modificar o tempo é da mesma forma, capaz de construir o vazio, e transmutar o que já passou. Consequentemente, entendemos que essa discussão teológica está fundada num paradoxo, pois a própria lógica passa a ser negada pela ideia do poder absoluto de Deus. Em suma, o criador é capaz de reverter à lógica formal do universo e instaurar novas formas, entre elas, o vazio. Postula-se, assim, uma concepção de forma total hipotética e hermenêutica. O entendimento dessa ideia de forma não comporta fechamento, mas se costura em um paradoxo teológico. 


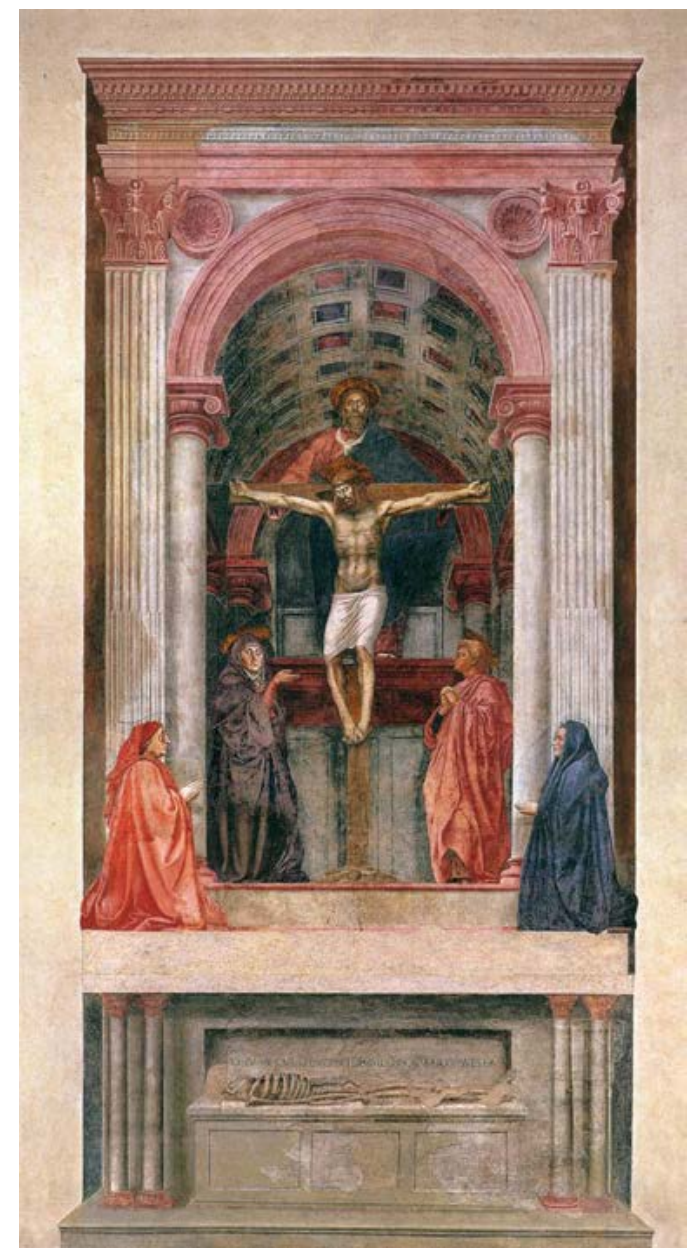

Fig. 2 - MASACCIO. Trindade. Afresco, $667 \times 317 \mathrm{~cm}$. Florença, Igreja de Santa Maria Novella Fonte: ARGAN, Giulio Carlo. Clássico Anticlássico: O Renascimento de Brunelleschi a Bruegel. São Paulo: Companhia das Letras, 1999.

De fato, esse teorema doutrinário acaba induzindo outras possibilidades interpretativas acerca do Todo. O Todo é, hipoteticamente, variável e mutável, segundo o anseio da onipotência divina. Entretanto, não há mudanças no universo porque Deus tem a onisciência de seus desejos. Não há por que mudar, já que sua decisão é acertada. Mas a onisciência não exclui a onipotência: caso quisesse, Deus poderia restaurar a virgindade de uma mulher.

Verifica-se, portanto, um contexto de liberdade hermenêutica da igreja católica. Seguramente, a discussão sobre a onipotência divina funcionava como interstício epistemológico, dando a ver novas interpretações no pensamento teológico da imagem. O breve comentário do historiador serve apenas para localizar uma inquietação naquela cultura. Inquietação que será verificável na vontade de síntese dramática de Giotto (organizando o quadro em torno de uma cena narrativa, na busca de valorizar o acontecimento) e na pulsão plástica de Masaccio e Brunelleschi, ambas em busca de uma forma total que se revela de modo singular para cada um dos artistas. A aproximação desses artistas em torno da forma do crucifixo se dá do seguinte modo:

Masaccio representa a ação humana enquanto ação histórica - uma retomada dos grandes temas de Giotto. Com efeito, o espaço de Giotto não é topográfico, mas nasce da ação que o determina ao cumprir-se. A ação torna-se assim reveladora de uma ordem ética. Um século mais tarde, em Masaccio, 
a ação histórica é reveladora da ordem natural, porque se cumpre segundo uma coerência absoluta de causas e efeitos. Masaccio recomeça de Giotto - para ir em frente, retrocede (analogamente, a arquitetura de Brunelleschi é, por muitos aspectos, um revival da arquitetura românica toscana, como oposição a fragmentação do gótico tardio) (...) (ARGAN, 2011, p. 43).

O comentário de Giulio Carlo Argan diz respeito à obra de Masaccio intitulada Trindade (figura 2), na qual Cristo está numa cruz colocada em um espaço arquitetônico que se assemelha a uma cúpula - em referência explícita a Brunelleschi. Diz a tradição crítica que Masaccio teria aprendido perspectiva com o arquiteto Filippo Brunelleschi. Tanto que Giorgio Vasari comenta que o arquiteto disse próximo à sua morte a seguinte sentença: "Masaccio foi para nós uma imensa perda", e prossegue Vasari ajuizando: "perda que foi muito dolorosa para aquele que se empenhou duramente muito tempo em ensinar-lhe muitos princípios de perspectiva e arquitetura" (VASARI, 2011, p. 223). Dentro do espaço topográfico, Masaccio retoma o tema de Giotto (a crucificação), apresentando a ação histórica (tão perseguida pelo pintor dos trezentos) segundo a coerência da ordem natural. Argan chega a dizer que, mais do que tradição, o que se observa na operação de Masaccio é um revival de Giotto. Esta palavra parece crucial para que se compreenda que Masaccio, apesar de aluno de Masolino, não obedece à progressão contínua desta linhagem, mas se agiganta como artista da primeira metade dos quatrocentos por ter voltado a Giotto, revitalizando a obra do mestre do passado. Trata-se, portanto, da questão de representação histórica de um tema (a crucificação), inserido em uma cultura em que se buscam criticamente possibilidades de releitura/recriação da imagem não apenas pelo viés técnico e temático, mas por meio de um olhar teorético diante do fato representado. Mais do que a técnica de Giotto, interessa a Masaccio a visão intelectual deste pintor ante o fato histórico, e ele o aborda com toda a sua sensibilidade sintética de organização do quadro por meio de uma unidade ética. Argan diz:

\begin{abstract}
Masaccio compreende que, para expressar o verdadeiro sentido do dogma, é preciso representar na mesma cena a causa e o efeito, até torná-los idênticos. Assim, essa trindade, toda construída por triangulações espaciais, não ilustra seu tema, mas o representa estruturalmente. Consegue evitar o símbolo e a alegoria, substituindo-os por uma representação que encarna e torna evidente por si mesma (ARGAN, 2011, p. 43).
\end{abstract}

Anteriormente as imagens cristãs eram aceitas apenas como mediação, instrumento de mensagem do Evangelho, não devendo forjar a representação da realidade; por isso, o veto ao uso das esculturas por sua força tridimensional e a permissividade das pinturas como representação figurada das escrituras no início do cristianismo (GOMBRICH, 2012, p. 135). Na passagem, a perspectiva é apresentada em relação direta com o dogma religioso da trindade. As triangulações espaciais de base perspectiva dão a ver a trindade representada dentro de um espaço arquitetônico brunelleschiano. O espaço matemático e plástico põe a imagem de Cristo de modo evidente, quebrando qualquer alegoria e simbolização. Há, portanto, uma ordem "natural" edificada por essa representação que oferece ao observador a evidência de uma imagem verdadeira. Não existe tampouco a simbologia alusiva da cruz e nem o 
jogo alegórico de dizer " $x$ " para significar " $y$ ". O caso do crucifixo de Masaccio torna-se, assim, exemplo dessa capacidade direta de significar o conteúdo dogmático, no qual a perspectiva passa a ser vista como forma de representação verdadeira. Sendo assim, a perspectiva linear é um paradoxo, porque ela se apoia no espaço geométrico, matemático e, consequentemente, imutável para representar um acontecimento imanente e real. Argan prossegue:

A representação de Cristo em figura humana é antiquíssima, mas, além de Masaccio, não se conhecem casos de um Deus Pai expresso tão claramente em sua totalidade. $O$ eterno é representado, ele também, num aspecto fenomênico antropomorfo; precisa até de um plano para se manter de pé. Fora do espaço, excluídos, estão os dois patrocinadores da obra: o espaço arquitetônico que abarca a Trindade é por definição um espaço sagrado, absoluto, o espaço da teogonia (ARGAN, 2011, p. 43).

Na Trindade de Masaccio, o espaço da cúpula torna-se o espaço da teogonia (teo, Deus, gonia, nascimento). Assim, Argan explica a presença do espaço arquitetônico e seu caráter "metafísico". Metafísico por ser sagrado (separado) devido ao seu caráter matemático e geométrico, mas relacionado ao dogma religioso da forma total. Contudo, essa sacralização se ancora no mundo concreto das construções. No quadro, Cristo não está no monte do calvário como costumeiramente o vemos localizado, mas sim em um espaço calculado. Em parte, esta geometrização do espaço expressa a ideia de um mundo fora da fisis - abstrato. Por outro lado, a presença da arquitetura reforça o aspecto de uma espacialidade construída, que não é "natureza", e que pode ser capaz de dar conta de uma racionalidade universal. Quando Argan diz que Masaccio revela a ordem natural, esta revelação, seguramente, não deve ser entendida como a visão de uma realidade cotidiana, mas como a demonstração visual da racionalidade desta ordem natural.

Não há ilusionismo, tudo é realidade manifesta, e a aplicação de uma perspectiva extremamente precisa demonstra o valor que se atribuía, naquele momento, à perspectiva: um espaço privilegiado, puramente racional, fora da existência e dos aspectos transitórios das coisas (ARGAN, 2011, p. 43).

"Não há ilusionismo em Masaccio": esta afirmação precisa ser pensada com cuidado. Ela parece se confrontar com a discussão acerca da representação da perspectiva no Renascimento nos ensinamentos de Erwin Panofsky, nos quais o historiador alemão afirmou existir uma antinaturalidade deste espaço no que se refere à sua condição psicofísica (PANOFSKY, 1999, p. 32). Cabe reforçar aqui que a recepção natural (psicofísiológica) não é semelhante ao conceito de "ordem natural" conforme apresentado por Argan. A perspectiva linear causava estranhamento psicofísico, embora demonstrasse um princípio de ordenação lógica da natureza (por meio de uma leitura teorética e matemática do mundo). Dessa forma, a declaração do historiador italiano não está necessariamente em desacordo com a hipótese de Panofsky. Ela está simplesmente amparada em outro ponto de vista teórico. Assim sendo, se a perspectiva não satisfazia ao mimetismo psicofísico deste contexto histórico, processava-se nela, de outro modo, uma inteligibilidade do mundo mais profunda e racional 
que, como Giulio Carlo Argan nos diz, exibe a "ordem natural" do mundo. Ordem que não se refere ao código naturalista de representação mimética e psicofísiológica, mas à disposição do mundo em sua totalidade. Daí a forma geométrica deste espaço não poder ser lida como ilusionista a partir desta perspectiva teórica.

Tal construção é anti-ilusionista não por ser planar, como é o caso da pintura moderna, mas por ser relacionável ao conceito de Uno presente na filosofia neoplatônica, que liga o ser absoluto ao conceito de infinito. Assim sendo, a perspectiva linear representaria uma possibilidade de entendimento desta filosofia que propõe a aproximação de dois conceitos difíceis de serem aproximados: o todo e o infinito. Isto porque o todo traz a acepção de completude da forma, enquanto o infinito expressa a imagem de informe, o ilimitado (ápeiron - ä $\pi \varepsilon \imath \rho o v$ ).

A compreensão do Uno encontra-se presente na tese de Plotino, em seu conhecido escrito Enéadas. A este respeito, Giovanni Reale, historiador da filosofia, diz que tal conceito abarca a ideia de infinito no neoplatonismo. O estudioso explica também que esta categoria não teria sido aceita positivamente por Platão e Aristóteles (REALE, 2008, p. 40-50). Tanto para Platão quanto para Aristóteles, o infinito comportava o não ser, ou seja, o ilimitado. Segundo Giovanni Reale, Plotino dá à categoria do Uno as seguintes características: "O Uno está acima do ser (da ousía e da essência), acima do pensamento e também acima da vida" (REALE, 2008, p. 49). Assim, o Uno é uma espécie de potência, uma anterioridade absoluta e, por isso, podemos aproximá-lo do conceito de onipotência divina de São Pedro Damião ${ }^{1}$. É provável que esteja aí o segredo da afirmação de Giulio Carlo Argan citada há pouco. Vê-se a imagem de um Deus absoluto e Uno cuja propriedade representativa como pintura é edificada através da perspectiva linear, com sua projeção para o espaço infinito. Em função da escolha desse raciocínio estratégico, Argan diz que não existe ilusionismo. Há, portanto, a "realidade manifesta" de uma trindade absoluta. E não há ilusionismo até porque Argan acredita, como Panofsky, que a imagem da trindade era vista com distância, uma vez que no contexto histórico de seu surgimento não era comum esse modo de construção pictórica.

Todos esses conceitos filosóficos, assim como o ressurgimento de Platão (via neoplatonismo) e Aristóteles (via São Tomás de Aquino) no contexto deste primeiro Renascimento, não devem ser compreendidos como mote de leitura definitiva. A apropriação das ideias pela história da arte não obedece a uma lógica normativa. Nesse caso específico, interessa-nos alcançar como essa discussão filosófico-teológica nos faz entender um horizonte de possibilidades para a representação do divino no contexto do Renascimento. A respeito dessa filosofia de base cristã, é necessário que se compreenda como ela, ao se ver entrelaçada na religião e nas interpretações exegéticas da forma e da racionalidade vigente (ancorada no paradoxo inquestionável da onipotência divina), fundamenta uma práxis para esse mundo florentino.

Há uma diferença que deve ser frisada: a crítica moderna nomeia o espaço perspectivo como ilusionista porque já parte da sua naturalização, e a "pintura pura" da arte moderna proclama a planaridade do espaço na busca por subverter este aspecto

$1 \quad$ Há um primeiro momento da Escolástica Medieval muito ligado ao pensamento de Santo Agostinho. São Pedro Damião faz parte desse momento. Sabemos que Santo Agostinho leu Platão a partir de Plotino. Por isso, estamos propondo esta rápida associação entre Plotino e São Pedro Damião. 
ilusionístico. Entretanto, o que se observa na manobra crítica de Giulio Argan é a procura por uma verossimilhança histórica da experiência desse espaço no contexto renascentista. Daí o anti-ilusionismo apresentado e defendido pelo historiador.

No comentário de Giorgio Vasari, apreende-se algo próximo do argumento apresentado por Argan: "Assim, tudo o que foi feito antes dele era realmente pintado e pintura, ao passo que as obras, em comparação com as de seus concorrentes e com as daqueles que quiseram imitá-lo, parecem vivas e verdadeiras, e não imitações da natureza" (VASARI, 2011, p. 218). No trecho desse historiador do século XVI, percebe-se o quanto essa questão da representação era cara ao Renascimento. Havia um veto em relação à mímesis, uma vez que esta expressava uma cópia diminuída da natureza - entendida como mundo sensível e perecível. Porém, na Trindade de Masaccio, a presença da forma geométrica da perspectiva linear expressa parcialmente o real imutável do mundo das ideias; justamente porque é forma total, evidência (como na exposição defendida por São Pedro Damião, como diz Argan) e não pintura como mera imitação da natureza (mundo perene).

Diferente da discussão filosófica de Giulio Carlo Argan, Ernst Gombrich, em seu livro A história da arte, também segue o mote panofskiano acerca do estranhamento que o espaço pictórico criado por Masaccio produzira naquele contexto florentino. Gombrich diz: "Tal revolução não se constitui apenas no estratagema técnico da pintura em perspectiva, embora isso, por si só, deve ter sido deveras espantoso enquanto novidade" (GOMBRICH, 2012, p. 229). De fato, há nesta passagem do historiador austríaco um esforço de perceber o caráter de novidade dessa criação, como experiência sensível do homem do Renascimento. Em seguida, Gombrich prossegue em seu raciocínio, incluindo Brunelleschi: "Podemos imaginar a perplexidade dos florentinos quando esse mural foi exposto e parecia um buraco na parede através do qual podiam ver uma capela no moderno estilo de Brunelleschi" (idem, p. 229).

O exercício imaginativo-teórico de Gombrich expõe, em alguma medida, a concretude da descoberta perspectiva da arquitetura de Brunelleschi, desdobrada no mural de Masaccio, funcionando como uma espécie de "buraco" a se abrir perante a percepção do espectador. Apesar de não ligadas diretamente, a descrição de Gombrich nos faz compreender mais a afirmação de Vasari, principalmente quando este opunha a criação do espaço edificado por Brunelleschi e Masaccio às "pinturas" - estas sendo, para ele, meras reproduções da natureza². Há nesse comentário de Gombrich uma espécie de reconstituição da sensibilidade histórica do Renascimento. Em Vasari, a experiência da perspectiva é mencionada já como uma norma abraçada e a ser seguida - e devemos ter em mente que mais de um século separa a descoberta do espaço brunelleschiano e seus escritos (VASARI, 2011, p. 218). Já Gombrich descreve, a partir de sua base historiográfica (absorvendo a tese de Panofsky), uma hipótese da recepção visual do espectador da época, captando o frescor dessa espacialidade no momento de sua invenção.

Até agora estamos diante de três vetores teóricos: Vasari defende a representação verdadeira do espaço transformado em norma; Gombrich descreve uma recepção

$2 \quad 0$ conceito de "pintura" para Vasari diz respeito à cópia da natureza. A geometria espacial de Masaccio e Brunelleschi apresenta-se como a manifestação de uma realidade formal. Argan capta esse sentido presente no quadro, e por isso propõe a ideia de forma total para pensar a Trindade de Masaccio. Realidade formal que provoca, contudo, estranhamento, pois não é naturalizada pela sensibilidade do período. 
hipotética do olhar para a Trindade de Masaccio; Argan adentra o âmbito de uma discussão filosófica acerca da representação com o objetivo de tocar no valor ético e artístico da invenção de Brunelleschi e Masaccio.

O fato de a representação ser mencionada como ilusória ou não remonta ao debate platônico acerca do veto à mímesis dos poetas e seu ilusionismo, na célebre passagem do livro $X$ de $A$ república. Neste livro, o filósofo grego dá um veredito negativo à cópia feita pelos artistas. Ocorre que há uma mudança de orientação e de interpretação no que tange à tradição do neoplatonismo, no que se refere ao veto à representação por parte dos artistas. E se, no tempo de Brunelleschi e Masaccio, o Renascimento não seguia ainda a construção teórica de Marsílio Ficino ${ }^{3}$, de um belo incorpóreo, havia já nessa época a ênfase no caráter formal e matemático como a possibilidade de manifestação da verdade no mundo sensível: a matemática era a disciplina do terreno da evidência. Logo, a forma geométrica passa a ser vista como não ilusória por atender ao princípio imutável do mundo das ideias. Esse debate parece ser interminável, até porque a própria noção de forma que esta tradição recebe de Platão já se vê modificada, caso possamos nos deter nas sutis alterações propostas pelo pensamento neoplatônico. Sutilezas que, vistas de perto, como nos mostra Giovanni Reale, nos oferecem uma visão bem diversa daquela proposta por Platão.

Eis, portanto, o paradoxo do "formalismo" do Renascimento: idealismo neoplatônico convivendo com um mundo em fervilhante transformação de sua estrutura teológica; fato que vai exigir de seus artistas uma ação interpretativa. Mesmo a concepção de forma total é antes um mote prático religioso do pensamento cristão, teorizado por São Pedro Damião acerca da onipotência de Deus em restaurar a virgindade de uma jovem, tema cristão por excelência e ao mesmo tempo prosaico.

\section{A Adoração dos magos: as versões}

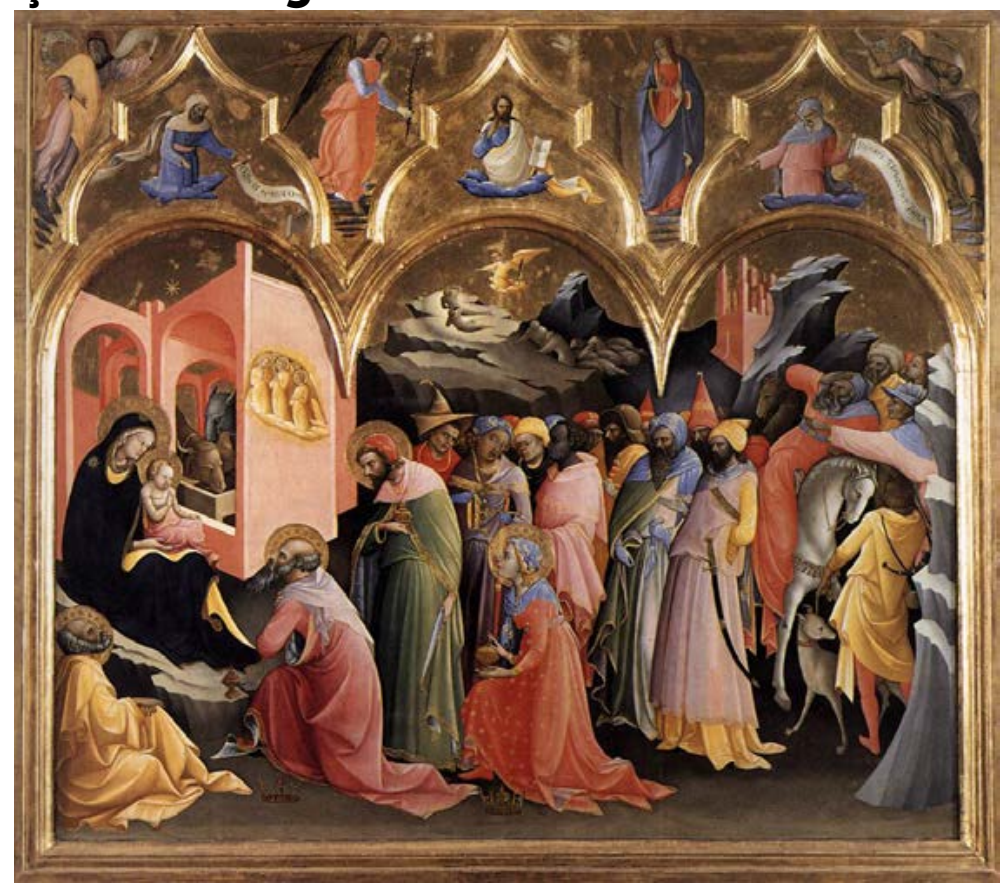

Fig. 3 - MONACO, L. Adoração dos Magos. Têmpera sobre madeira, 144 x 177cm. Florença, Galeria dos Ufizzi.

Fonte: ARGAN, Giulio Carlo. Clássico Anticlássico: O Renascimento de Brunelleschi a Bruegel. São Paulo: Companhia das Letras, 1999.

3 Marsílio Ficino (1433-1499) foi um importante pensador do humanismo florentino e grande divulgador do pensamento platônico no Renascimento. Na segunda metade dos quatrocentos, influenciou nomes como Sandro Botticelli (1445-1510), Leonardo da Vinci (1452-1519), entre outros. 
Giulio Carlo Argan, ao analisar as três versões da Adoração dos magos, de Lorenzo Monaco, de Gentile da Fabriano e de Masaccio (figuras 3, 4 e 5), mostra a diferença de interpretação de cada um dos artistas. Os três pintores são figuras singulares de sua época, e cada um deles se aproxima de um grupo social específico: Monaco, dos religiosos da regra de Camaldoli; Fabriano, da burguesia; e Masaccio, da alta burguesia.

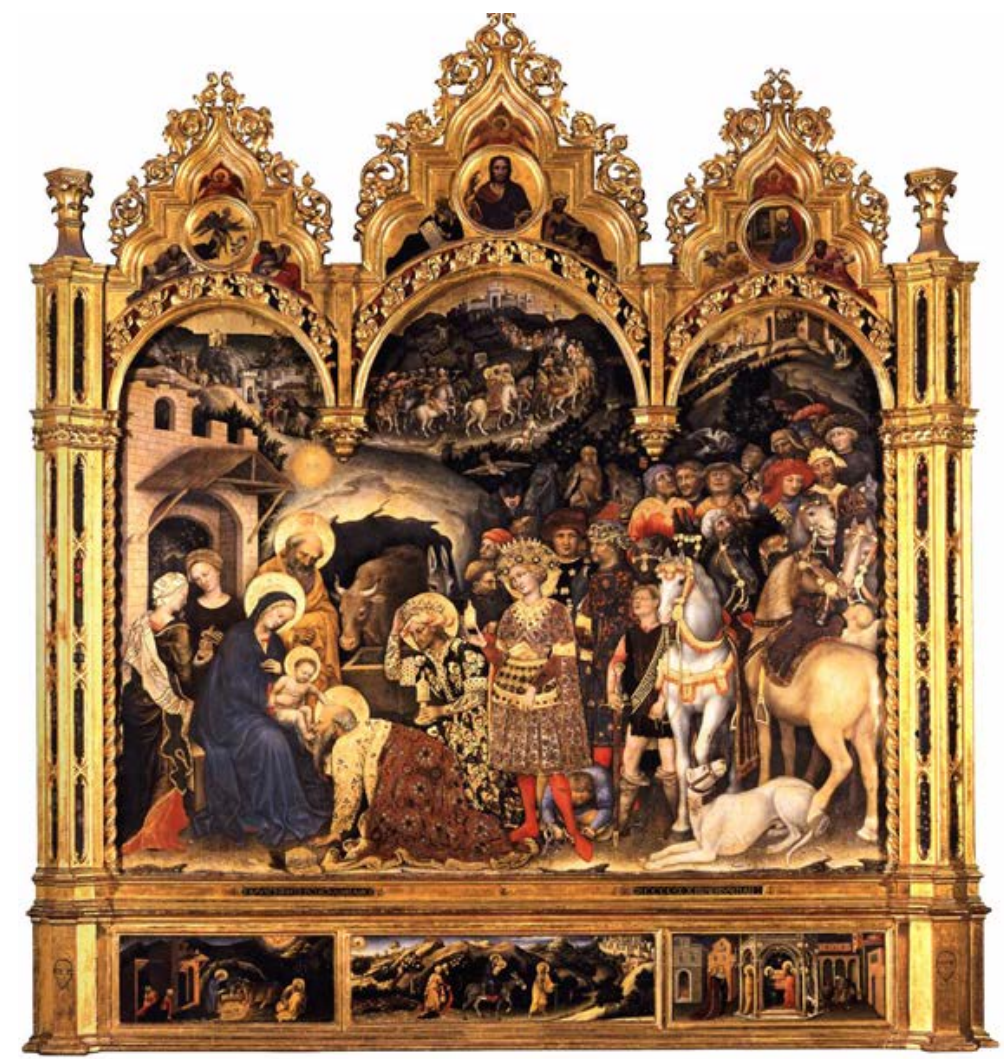

Fig. 4 - FABRIANO, G. Adoração dos Magos. Têmpera sobre madeira, 203 x $282 \mathrm{~cm}$. Florença, Galeria dos Uffizi

Fonte: ARGAN, Giulio Carlo. Clássico Anticlássico: O Renascimento de Brunelleschi a Bruegel. São Paulo: Companhia das Letras, 1999.

Na passagem em que cuida da Adoração dos Magos, Argan cita duas vezes o historiador marxista Frederick Antal em seu célebre livro Florentine painting and its social background. Em seu comentário, o historiador interpreta a obra dos artistas tendo como pano de fundo a interpretação de Antal. Nos dois momentos em que Argan cita e comenta a obra de Antal, ele ajuíza acerca da tese sociológica deste estudioso, afirmando o aspecto secundário da lógica das classes sociais na fundamentação crítica da obra de arte. O primeiro momento refere-se à interpretação de Antal da obra de Lorenzo Monaco.

O aspecto sociológico do quadro foi investigado por Frederick Antal em seu livro Florentine painting and its social background [a pintura florentina e seu ambiente social], partindo das posições religiosas das regras dos Camaldoli, a que Lorenzo Monaco pertencia, o autor aponta para a convergência de elementos aristocráticos e populares (dois planos sociais já fundidos por Giotto como, de resto, por Dante) (ARGAN, 2011, p. 38).

Neste primeiro momento, Argan não irá negar o aspecto sociológico apontado por Frederick Antal, apenas salientará o quanto as convergências de planos aristocráticos e populares já haviam sido fundidas anteriormente por Giotto e por Dante 
(certamente, Argan se refere nesse comentário à tese notória de Eric Auerbach) ${ }^{4}$. Por essa afirmação, podemos suspeitar que o historiador italiano esteja mostrando sutilmente que, pelo viés sociológico, não é privilégio de Lorenzo Monaco a fusão de estilos, e sim que ela já foi processada um século antes por Giotto e Dante. De fato, o historiador italiano não considera o princípio do fato artístico como condicionado pela ideologia, mas, para ele, a arte tem o poder de inaugurar novas formas de pensar, sendo antes condicionante do meio cultural (ARGAN, 2011, p. 39). Para o historiador húngaro, "artistic style is primarily an expression of ideology, political beliefs and social class" [o estilo artístico é essencialmente uma expressão da ideologia, das crenças políticas e da classe social do artista] (ANTAL, 1975, p. 87). Observa-se, nesta breve passagem, uma diferença de postura crítica dos dois pensadores. Essa divergência está presente no modo como Argan, propositalmente, reinterpreta obras antes analisadas por Antal.

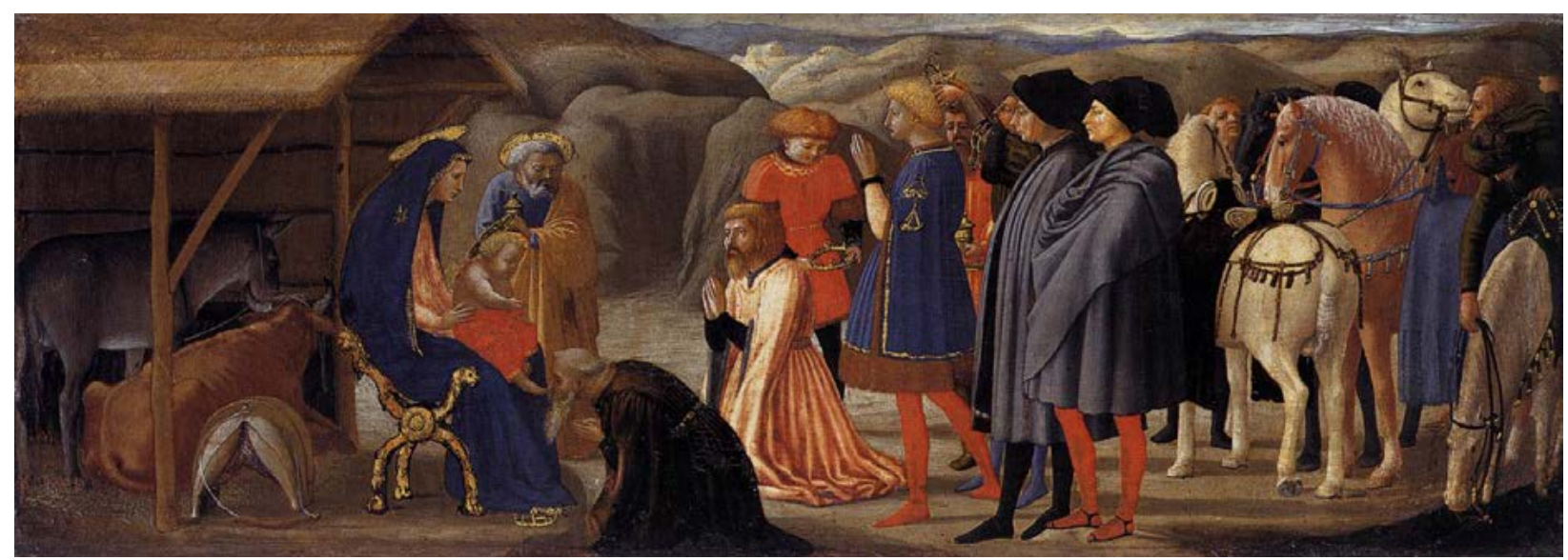

Fig. 5 - MASACCIO. Adoração dos Magos. Têmpera sobre madeira, $21 \times 61 \mathrm{~cm}$. Berlim, Staatliche Museen.

Fonte: ARGAN, Giulio Carlo. Clássico Anticlássico: O Renascimento de Brunelleschi a Bruegel. São Paulo: Companhia das Letras, 1999.

Giulio Carlo Argan faz as seguintes operações descritivas sobre o trabalho de Lorenzo Monaco: 1ㅇ - indica o contexto social do artista - a regra dos Camaldoli; 2 ㅇ - aponta as particularidades formais do quadro - "as cores são fortemente marcadas, límpidas, diferenciadas umas das outras, duras e cristalinas"; "os contornos são cortantes e emagrecem as figuras, buscando ritmos de curvas tensas" (ARGAN, 2011, p. 38); 3 - observa a organização narrativa do quadro - "a personagem, ainda a cavalo, que põe a mão na testa e olha ao longe, talvez para a aparição da estrela" (idem, p. 38). Contexto social religioso, descrição detalhada da plasticidade do quadro e percepção aguda sobre a operação processada na composição narrativa da temática bíblica ${ }^{5}$ expõem estruturas diferenciadas. Assim, o crítico transpassará cada uma dessas camadas (contexto social, descrição formal e disposição temática) em busca de uma categoria de análise (imagem-crítica) que atravesse cada uma das partes sem subordinar a interpretação do quadro a uma visada sociológica, formalista ou retórica. Argan não

Sobre a quebra dos níveis da retórica clássica, Eric Auerbach diz: "Antes, tanto durante a Idade Média toda como ainda no Renascimento, houve um realismo sério; tinha sido possível representar os acontecimentos mais corriqueiros da realidade num contexto sério e significativo, tanto na poesia como nas artes plásticas; a doutrina dos níveis não tinha validade universal" (AUERBACH, 2011, p. 500). A tese de Auerbach sobre a mímesis localiza no Renascimento e principalmente na obra de Dante a operação da síntese do alto e do baixo provenientes da separação da retórica clássica em alto, baixo e médio (a tragédia significava o alto e o sério; o baixo era concebido através do gênero cômico; e o médio, os temas de amor carnal - uma espécie de taxonomia entre a cabeça, 0 tronco e a pélvis).

5 No caso, a justaposição de uma cena do passado no primeiro plano do quadro - um mago vendo a estrela, já próximo à cena da visitação. 
abandona, portanto, os métodos analíticos e formais de descrição da obra, mas não submete seu juízo a esses métodos.

A partir dessa descrição, Giulio Carlo Argan, como crítico rigoroso, perscruta, na Adoração dos Magos de Lorenzo Monaco, sua potência e valor estético. E chega a um mínimo divisor comum: a viagem. Ele diz:

\begin{abstract}
A "viagem" possui um significado preciso, é o tema da esperança, da aspiração a uma meta e do itinerário que é necessário percorrer para alcançar o ideal. O tema da viagem é, portanto, um sintoma das aspirações, da espera, é a inserção de um elemento ascético numa representação de caráter histórico e alusivo. Esse caráter ascético reflete-se no tratamento essencial dos particulares (para tomar distância do aspecto mundano do gótico internacional) (ARGAN, 2011, p. 38).
\end{abstract}

O termo "viagem" passa a ser uma imagem crítica da qual Giulio Carlo Argan extrai um sentido amplo do quadro de Lorenzo Monaco, uma vez que o vocábulo toca na ascese espiritual do religioso, na pureza dos contornos das figuras e na construção retórica do quadro. De fato, essa imagem que emerge do juízo do historiador está em relação com os outros dois quadros que serão analisados em seguida por Argan: o de Gentile da Fabriano e o de Masaccio. Analisando a obra de Monaco, o historiador também descreve a paisagem ao fundo do quadro, mostrando o quanto ela é propositalmente selvagem: "os rochedos são ásperos como garras" e as "montanhas longínquas". Por isso, "a terra não salva, a natureza é dificuldade, barreira entre o homem e sua aspiração à transcendência" (ARGAN, 2011, p. 39).

Se a viagem encaminha o homem à transcendência, e se a natureza é limite, concebe-se que a imagem temática escolhida pelo crítico está calcada em uma ação de ascese. Não há viagem mundana, e sim uma viagem espiritual, como a dos Reis Magos em direção ao Salvador. Seguramente, Argan busca o valor do quadro em conformidade com a religiosidade de Frei Lorenzo Monaco, já considerada como valor por Giorgio Vasari em seu livro Vidas dos artistas. Porém, na leitura de Giulio Carlo Argan, essa religiosidade do Frei não é diminuída por um preconceito marxista (ou por qualquer predisposição filosófica niilista) e tampouco "mitologizada" como em Vasari, vista em uma redoma ideológica católica (VASARI, 2011, p. 161-163). Essa religiosidade é limite, sim, mas é a condição de construção e de interpretação crítica desse artista, visto que, para Argan, já há em Lorenzo Monaco, mesmo sem a intensidade de um Masaccio, a força crítica de um artista pertencente ao contexto do Renascimento. Assim sendo, a operação de Argan busca captar o valor estético do quadro do artista sem prendê-lo a dogmas teóricos.

A relação criada pelo historiador entre o quadro de Lorenzo Monaco e o de Gentile da Fabriano constrói-se na articulação entre a viagem e a caça. As duas ações são determinantes para que Giulio Carlo Argan formule sua interpretação das obras, mas sabemos que essas categorias são extraídas mediante uma posição comparativa e crítica entre os quadros desses dois pintores, sendo a obra de Masaccio o vértice da análise. Observemos o modo como Argan processa em seu texto essa articulação entre Monaco e Fabriano: "Para Gentile da Fabriano, ao contrário, a natureza é uma realidade total, onde o homem vive e encontra, inclusive, sua salvação espiritual. Lorenzo 
Monaco escolheu uma regra ascética; Gentile da Fabriano é um leigo" (ARGAN, 2011, p. 39). Tal passagem é significativa, visto que a partir dela percebemos que o valor interpretativo de Giulio Carlo Argan surge da comparação, e não está submetido a um princípio epistemológico engessado - dando-se, portanto, em relação.

Argan chega ao tema da caça em Gentile da Fabriano do seguinte modo:

A chave para entender o quadro de Gentile da Fabriano não é a "viagem" como em Lorenzo Monaco, mas a caça, ocupação favorita das cortes. Gentile misturou cães, falcoeiros e pajens à cena religiosa. É uma representação cortesã ou cortês, tanto que, mesmo incluindo a gruta, o pintor sentiu a necessidade de transformar as duas mulheres que ajudam no parto em duas damas elegantíssimas. São realçados até aspectos insignificantes da vida cavalheiresca: no primeiro plano, há um pajem que tira as esporas de seu senhor (ARGAN, 2011, p. 40).

A imagem crítica da caça em Gentile da Fabriano é observada atentamente pelo historiador. A partir dela e de sua contextualização na cultura cortesã, Argan analisa o quadro do pintor modelar do gótico internacional, comentando aspectos compositivos como o caso das jovens damas cortesãs no lugar de servas (uma vez que Jesus é de origem pobre); a diversidade de detalhes nas figuras que Fabriano aprendera com a tradição de Simone Martini (do desenho autográfico), cujo traço é enriquecido por uma gama de riscos e linhas que, ao invés da pincelada pura de Lorenzo Monaco, produz uma experiência de beleza calcada na variedade. Argan faz o mesmo que já fizera ao unir o tema da viagem à pintura pura e ascética de Lorenzo Monaco. Porém, aqui, é a experiência da caça e sua relação direta com a natureza que fazem com que ele explique a experiência estética singular da obra de Gentile da Fabriano. Na seguinte passagem, esta questão fica mais evidente:

A caça é essencialmente "naturalidade educada", é considerada uma vida ideal adequada às cortes. Sendo a forma de vida escolhida, é também um momento religioso (a revelação divina também é vista como algo reservado a privilegiados). Enfim, o ideal estético é sentido como ideal de vida (acontece agora no gótico internacional...); dessa forma é impossivel uma distinção entre arte e vida, é impossível conferir à arte uma função específica (ARGAN, 2011, p. 41).

A caça vista como "naturalidade educada" é um conceito crítico que acaba por se aproximar do ideal de vida cortesã. $O$ historiador nos mostra o quanto a referência à cultura cortesã da caça produz, no quadro de Gentile da Fabriano, uma indistinção entre a arte e a vida, uma vez que a arte serve ao ideal de vida daquela classe cavaIheiresca. No caso, o historiador está contrastando uma arte que se confunde com o modo de vida de uma classe social (cavalheiresco, de Gentile da Fabriano) e uma arte que conquista sua função específica autônoma (a de Masaccio).

Para Argan:

A adoração dos magos de Gentile da Fabriano (Florença/ Galeria Uffizi), de 1423, é um dos quadros mais estudados do ponto de vista sociológico (sobretudo por Antal, que associa essa obra ao período dos Albizi e propõe uma distinção entre o estilo "burguês" de Gentile da Fabriano e o alto-burguês de Masaccio). Observemos, entre parênteses, que as considerações sociológicas 
são válidas, desde que sejam aceitas de modo não determinista: que não se considere que o artista é apenas condicionado pelo ambiente social, porque amiúde é ele o condicionador (ARGAN, 2011, p. 39).

Na visão de Frederick Antal os artistas são vistos como condicionados sociologicamente, forma oposta à de Argan. Acerca deste condicionamento, o historiador húngaro faz o seguinte comentário sobre o Renascimento italiano: "a liberdade do artista, que naturalmente não existia no sentido moderno da palavra, ficava confinada aos limites rigidamente prescritos pela encomenda" (ANTAL apud ARGAN, 2003, p. 107). E continua: "em geral, era de praxe equiparar o pintor a um artesão; por isso, não havia razão para que houvesse mais liberdade no seu trabalho do que no do seu artesão" (idem, p. 107). O que Antal diz deve ser levado em conta, já que a liberdade de escolha de um Picasso não era a mesma da de um Masaccio - ambos eram inventores, mas por mais que o pintor espanhol pintasse por encomenda, sua obra não estava submetida a uma estrutura rígida de produção como a do pintor florentino. Por outro lado, o conceito de autonomia é sempre relativo historicamente e como nos mostra Argan é na exegese interpretativa do cristianismo que se encontra o valor crítico e formal das obras desse primeiro Renascimento.

Há uma passagem em que Argan fala sobre a Adoração dos Magos de Masaccio em contraposição à de Gentile da Fabriano:

A contraposição com a obra de Gentile da Fabriano não poderia ser mais clara. Masaccio diz que a arte não se identifica com a vida, mas está fora do espaço da vida, num outro espaço e num outro tempo claramente distintos. A arte não se identifica com o ideal da vida dos príncipes, aliás, não se identifica com nenhum tipo de vida (ARGAN, 2011, p. 42).

Neste fragmento, torna-se visível qual o objetivo do argumento de Giulio Carlo Argan: instituir uma relação entre as obras para chegar ao espaço construído por Masaccio. Espaço que não é somente perspectivo (unitário), mas sim revelador da autonomia da arte, seu lugar de distinção estética. Desse modo, a interpretação de Argan nos põe diante de questões historiográficas importantes que unem a descoberta do Renascimento à arte moderna, pois, para ele, a concepção moderna da arte como campo autônomo é herdeira dessa racionalidade surgida no Renascimento, mesmo que, às vezes, se mostre antagônica.

Assim, o intuito de Argan é suavizar rivalidades discursivas entre esses contextos e perceber as heranças deixadas pelo Renascimento à arte moderna. A obra de Masaccio revelaria outro ordenamento plástico, menos dependente de temas narrativos como os dos outros artistas que fizeram também leituras da Adoração dos Magos. 0 historiador sugere haver uma espécie de paralelo entre a perspectiva linear e a autonomia da arte. Evidentemente, há na sua análise um esforço crítico de contextualizar a descoberta da perspectiva naquela cultura, provocando, consequentemente, uma reavaliação da arte moderna quanto à importância do Renascimento italiano.

Percebe-se, portanto, o modo como Giulio Carlo Argan diferencia sua análise crítica da de Fredrik Antal, e como no historiador sobressai à dimensão da arte nesse contexto. Evidentemente, não faz sua interpretação desligada do contexto artístico 
italiano do Renascimento. Mas, por vezes, usa categorias, como as amadurecidas na reflexão da crítica de arte moderna, para analisar o período do protorrenascimento ou a presença de um espaço autônomo da arte no sentido de pensar a descoberta do espaço perspectivo brunelleschiano no quadro de Masaccio. Argan aproxima a história da arte moderna do Renascimento de um modo mais conciliatório do que comumente se vê na historiografia da arte. Ele faz esse arranjo crítico e historiográfico trazendo como base para o seu argumento o debate acerca da forma total de São Pedro Damião, a fluidez das interpretações dos temas cristãos no Renascimento desde o franciscanismo de Giotto, com a finalidade de alargar as bases de interpretação do período por meio de sua visada aproximativa e dialética com a arte moderna.

\section{0 tributo: o espaço ético}

"Já não há ordem narrativa e episódica, mas perspectiva ética" (ARGAN, 2011, p. 46). No momento em que Giulio Carlo Argan analisa o quadro de Masaccio chamado O Tributo de Pedro torna-se notória a relação construída pelo historiador entre o uso da perspectiva e a criação de um espaço ético. E o porquê de o espaço perspectivo ser visto pelo historiador como dotado deste atributo nos faz pensar sobre o sentido do conceito de ética na obra de Giulio Carlo Argan.

Masaccio fez uma escolha ética. Pintou uma ação a ser contemplada, refletida. Esta escolha revela-se por meio de uma experiência que é, ao mesmo tempo, ética e estética. Assim, Argan conduz sua interpretação do quadro do pintor florentino e, do mesmo modo, define como absolutamente ético o espaço perspectivo descoberto por Brunelleschi. Ético porque fruto de uma escolha, ou seja, de uma ação humana e histórica.

É importante refletir sobre a paisagem do quadro. Argan faz o seguinte comentário sobre ela:

Em que consiste a paisagem para Masaccio? Observe-se que essa pintura é pouco posterior à Adoração dos Magos de Gentile da Fabriano, que era o intérprete da variedade natural (uma poética que ainda será a de Ghiberti, na segunda porta do Batistério). Masaccio se interessa pela unidade. Sua primeira preocupação é passar máquina zero na paisagem variegada de Gentile, cortar as flores e os animais, buscando a forma unitária da realidade inteira, isto é, o espaço (ARGAN, 2011, p. 46).

O autor estabelece novamente uma comparação com Gentile da Fabriano. O pintor do gótico internacional é o exemplo de uma paisagem rica em variedade, enquanto Masaccio representa uma paisagem ordenada pela unidade perspectiva. Buscar "a forma unitária da realidade inteira" é buscar tocar o centro do problema ético, ou seja, a sua universalidade - sem se dispersar na variedade do mundo. Por isso, a escolha por um significado ético deve ser pensada e refletida, e ela faz parte dessa operação hierárquica de valor própria do uso da perspectiva por Masaccio. Argan diz acerca da operação criada por Masaccio no quadro:

Masaccio sabe que o milagre da moeda tirada da boca do peixe tem pouca importância, compreende que o significado ético do relato é outro, está na 
decisão de Cristo de fazer Pedro encontrar a moeda na boca do peixe, em sua imensa superioridade sobre o mundo burocrático romano (ARGAN, 2011, p. 46).

$\mathrm{Na}$ interpretação de Argan quanto à operação ética de Masaccio, há a opção de não enfatizar o milagre, reduzindo assim o componente sobrenatural e acentuando o aspecto histórico. Argan explica: "O significado é o contraste entre duas leis; a moral e a oficial. Diante da grandeza da postura moral que o humanista Masaccio é chamado a representar, a fábula do peixe tem importância reduzida" (ARGAN, 2011, p. 46).

Como um humanista, Masaccio não destaca o aspecto sobrenatural da passagem bíblica, mas põe em contraste o dilema do episódio bíblico no qual Pedro é questionado pelos publicanos sobre o fato de Jesus pagar ou não os impostos. Pedro, precipitadamente, dissera que seu mestre já havia pagado os impostos. Em seguida, Jesus o questiona sobre sua inverdade. Tal questionamento é seguido de uma lição moral, na qual fica evidente que os impostos não são corretos. Entretanto, Jesus opera o milagre da retirada da moeda de dentro do peixe e paga o imposto devido. Trata-se de uma passagem bíblica rica em contradições. O milagre poderia ser central, pois é uma espécie de reviravolta que acentua o poder divino de modificar a causa da natureza - o que reforçaria a onipotência divina. Mas Argan nota na escolha de Masaccio, a de centralizar a pintura no diálogo de Jesus com os discípulos, uma forma de dar medida humana ao episódio, transformando-o em fato histórico e não sobrenatural. Ou seja, a forma total da perspectiva linear desprende-se (sem se opor) de seu conteúdo metafísico (onipotência divina) e revela-se como uma ação humana, interpretativa e histórica da passagem dos Evangelhos.

Sobre esta afirmação, Argan diz precisamente: “Masaccio não quer pintar um episódio, mas uma história, e quer entender o seu significado ético profundo. Por isso, confere ao episódio do milagre apenas uma fração de segundo" (ARGAN, 2011, p. 46). Neste trecho, o termo "episódio" tem um sentido anedótico. Já a palavra "história" traz com ela um caráter verídico, que expressa à ideia de uma ação ética no mundo. A imagem da fala de Cristo com os discípulos está em primeiro plano, porque nela há uma lição moral. Percebe-se, assim, a concepção humanística do Renascimento se impondo, juntamente com a valorização da razão diante do sobrenatural - o que não pode ser confundido com a descrença no Divino (este não está sendo questionado). O milagre pertence a Deus. A história, aos homens. Eis a razão ética do humanismo no quadro. Não se pode, entretanto, generalizar esse contexto como um período cujo ceticismo domina a cena. O tributo de Pedro é, sobretudo, um quadro cristão.

Argan afirma: "Com a pintura de Masaccio tem-se, pela primeira vez, uma pintura sem gestos" (ARGAN, 2011, p. 47). A escrita de Argan ainda traz esse costume de elencar inícios e de dar caráter de exemplaridade às obras analisadas. Sem discordar da afirmação do historiador, mas refletindo sobre seu método de construção histórica, podemos nos apoiar no exemplo de Giotto, e ver que se trata de um pintor com uma característica altamente gestual. Diferentemente, a escolha compositiva de Masaccio pela ausência de gestualidade propaga uma gravidade moral e uma verossimilhança histórica ao acontecimento. "O pintor quer mostrar com isso que as pessoas estão na história muito mais pelo peso de seu valor moral do que pelo valor instantâneo do gesto. Masaccio vive num tempo que renovou a maneira de ver a realidade, uma maneira nova de ver o mundo" (ARGAN, 2011, p. 47). 
Em suma, a todo tempo o historiador nos mostra em camadas o quanto o espaço perspectivo se presta a uma reconfiguração do olhar e à escolha de uma ação ética, mesmo tendo como base os textos bíblicos do Evangelho de Cristo e os debates teológicos da época. Estes tornam-se "pré-textos" para a construção do dispositivo retórico do pintor que, agora, já é um artista liberal, uma vez que é um agente político dentro do mundo público do humanismo italiano. Se algumas noções como a hierarquização do espaço e a racionalidade da perspectiva não podem ser alteradas por Giulio Carlo Argan em sua revisão crítica do período, elas, contudo, passam a ter sentidos mais alargados no contexto do Renascimento italiano. Espaços matemático, ético e empírico são vistos em um contexto filosófico e exegético de um Renascimento cuja ideia de forma total se constrói por meio de uma querela teológica - essa também errática e histórica. Historicizar esses debates através de uma análise crítica das obras, dando a ver disputas interpretativas dos artistas, amplia não só o entendimento das obras, mas reinterpreta o contexto de próprio Renascimento.

\section{Referências}

ANTAL, Frederick. Florentine painting and its social background: the bourgeois republic before Cosimo de Medici's advent to power, XIV and early XV centuries. New York: Icon Editions/ Harper \& Row, 1975.

ARGAN, Giulio Carlo. Arte moderna. São Paulo: Companhia das Letras, 2008.

ARGAN, Giulio Carlo. Clássico anticlássico: o Renascimento de Brunelleschi a Bruegel. Trad. Lorenzo Mammì. São Paulo: Companhia das Letras, 2011.

ARGAN, Giulio Carlo. História da arte italiana: de Giotto a Leonardo. Volume II. Trad. Wilma de Katinszky. São Paulo: Cosac Naify, 2003.

AUERBACH, Erich. Mímesis: a representação da realidade na literatura ocidental. Trad. vários tradutores. São Paulo: Perspectiva, 2011.

CARVALHO, Mario A. Santiago de. Noção, medição e possibilidade do vácuo segundo Henrique de Gand. Revista Filosófica de Coimbra, Coimbra, Vol. 1, n. 2, p. 359-385. 1992. Disponível em: <http://hdl.handle.net/10316/14689>. Acesso em: 2 nov. 2017.

GOMBRICH, Ernst H. J. A história da arte. Trad. Álvaro Cabral. Rio de Janeiro: LTC, 2012.

PANOFSKY, Erwin. A perspectiva como forma simbólica. Trad. Elisabete Nunes. Lisboa: Edições 70, 1999.

REALE, Giovanni. História da Filosofia Grega e Romana I -VIII. Trad. Henrique Claudio de Lima Vaz e Marcelo Perine. São Paulo: Edições Loyola, 2008. 
RESNICK, I. M. Divine power \& possibility in St. Peter Damian 's De Divina Omnipotentia. Leiden, Netherlands: E. J. BRILL, 1992.

VASARI, Giorgio. Vida dos artistas florentinos. Trad. Luciano Belosi. São Paulo: Martins Fontes, 2011. 